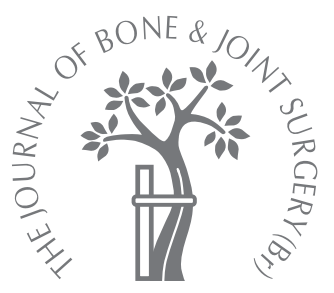

\title{
Review of Kinemax knee arthroplasty performed at the NHS Treatment Centre, Weston-Super-Mare
}

\section{P. J. Kempshall, A. Metcalfe, M. C. Forster \\ From Cardiff and Vale Orthopaedic Centre, Cardiff, Wales}

I. P. Kempshall, MRCS, SPR Trauma and Orthopaedics A. Metcalfe, MRCS, SPR Trauma and Orthopaedics M. C. Forster, FRCS(Orth), Consultant Orthopaedic Knee Surgeon

University Hospital of Wales, Heath Park, Cardiff CF14 4XW, UK.

Correspondence should be sent to $\mathrm{Mr}$ P. J. Kempshall; e-mail: Peterjkempshall@ hotmail.com

(C)2009 British Editorial Society of Bone and Joint Surgery doi:10.1302/0301-620X.91B2. $21609 \$ 2.00$

$J$ Bone Joint Surg [Br] 2009;91-B:229-33.

Received 29 July 2008 ; Accepted 22 October 2008

\begin{abstract}
As part of the government's initiative to reduce waiting times for major joint surgery in Wales, the Cardiff and Vale NHS Trust sent 224 patients (258 knees) to the NHS Treatment Centre in Weston-Super-Mare for total knee replacement. The Kinemax total knee replacement system was used in all cases. The cumulative survival rate at three years was $79.2 \%$ (95\% confidence interval (CI) 69.2 to 86.8 ) using re-operation for any cause as an endpoint and $85.3 \%(95 \% \mathrm{Cl} 75.9$ to 91.8$)$ using aseptic revision as an endpoint. This is significantly worse than that recorded in the published literature. These poor results have resulted in a significant impact on our service.
\end{abstract}

In Wales in 2004 the waiting time for total knee replacement (TKR) was approaching 36 months. In order to reduce this, the Welsh Assembly Government introduced the 'Second Offer Scheme' in April 2004, whereby no patient was to wait more than 18 months for in-patient surgical care, reducing to 12 months in March 2007. In order to be treated within this time patients had to travel for their surgery, with provision shared between the BUPA Hospital Cardiff and the NHS Treatment Centre at Weston-SuperMare. The Orthopaedic Department at the Weston-Super-Mare General Hospital is separate from the Weston Area Health NHS Treatment Centre. This paper relates only to the work carried out at this latter centre. The two organisations should not be confused.

In June 2006, Rhondda Cynon Taff Local Health Board, in agreement with Weston Area Health NHS Trust, invited the British Orthopaedic Association to carry out an independent review of the surgery performed at the Weston NHS Treatment Centre because the complication rate following surgery was higher than expected (Fig. 1). Their report concluded by making the following recommendations: ${ }^{1}$

1. The post-operative radiographs must be available for viewing by the operating surgeon before the patient or the surgeon leave the hospital.

2. There should be close communication between the surgical team and the rehabilitation services so that concerns can be identified and addressed at an early stage.
3. Ideally, one surgeon should oversee the three phases of pre-assessment, operation and follow-up.

4. Surgeons from the original hospital should be informed of problems that might arise.

5. The radiographs of all patients who have undergone joint replacement at the Weston NHS Treatment Centre should be reviewed, and for those found to be suboptimal the patient should be recalled for a further clinical and radiological check.

6. All patients treated at the Weston NHS Treatment Centre should be contacted and offered a clinical review if they have concerns about the outcome of their surgical treatment.

As a result of this report, this paper was written to compare the results of the surgery performed at the NHS Treatment Centre to those already published by other centres. The Kinemax total knee system (Stryker, Howmedica, Rutherford, New Jersey) has proved to be of robust design and has a reported survival at ten years varying between $96 \%$ and $97 \%$. $^{2,3}$

\section{Patients and Methods}

Between April 2004 and January 2006, 258 Kinemax TKRs were inserted for osteoarthritis in the Weston-Super-Mare NHS Treatment Centre by a variety of surgeons from Sweden supplied by Scanloc Medical Recruitment (Scanloc, Battle, United Kingdom). All 224 patients were contacted by telephone or letter, and offered clinical and radiological review, which was performed by one of the Cardiff and Vale NHS Trust consul- 


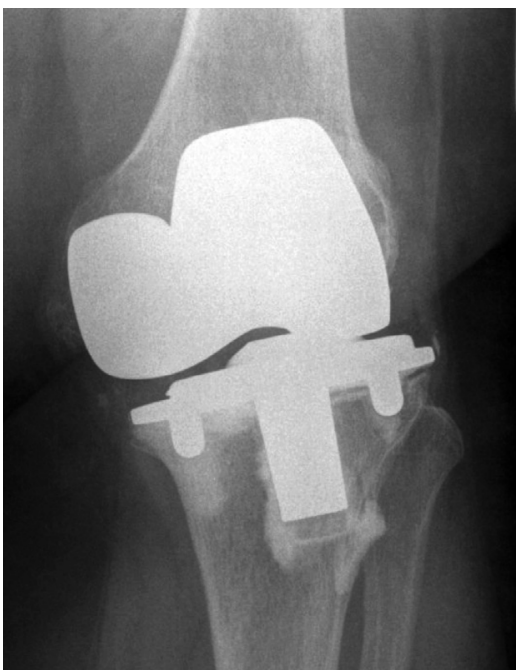

Fig. 1a

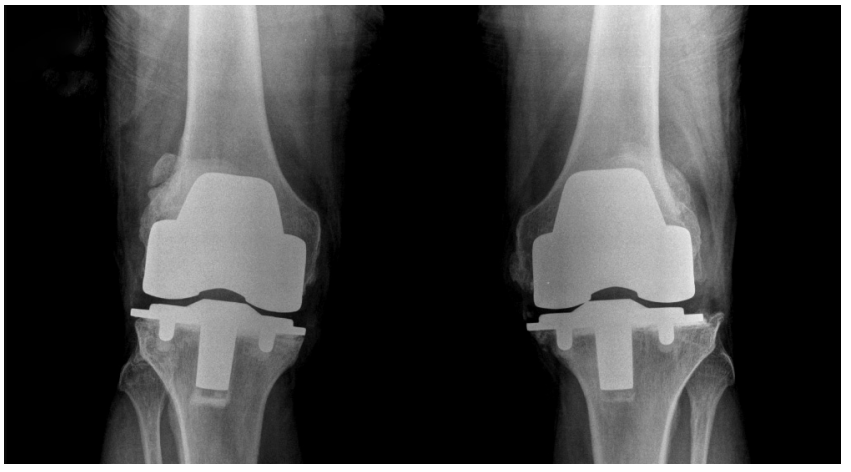

Fig. $1 b$

Anteroposterior radiographs of three knees a) 28 months post-operatively showing $14^{\circ}$ of varus of the tibial component and $18^{\circ}$ of valgus of the femoral component and b) bilateral varus tibial cuts with matching valgus femoral cuts at 26 months post-operatively.

tant knee surgeons. The radiographs of the patients were reviewed using the IMPAX (AGFA) image software (Agfa Health Care UK Ltd, Brentford, United Kingdom) and the positions of the components were assessed according to the Knee Society Scoring System described by Ewald. ${ }^{4}$ Angles were measured using IMPAX digital templating software (Medi CAD, Altfraunhofen, Germany). Data concerning revision, recommendation for revision and follow-up were taken from the patients' notes.

The radiographs were evaluated for varus malalignment, the degree of posterior slope of the tibial component, valgus malalignment and flexion of the femoral component, oversizing of the components resulting in reduced range of movement, or 'overstuffing' of the patellofemoral joint and overlapping of the tibial tray. The cement-component interface was also evaluated for radiolucent lines and signs of loosening of the components.

For the survival analysis a 'life-table' method was used as described by Armitage and Berry. ${ }^{5}$ This allows the analysis of data from patients with differing durations of follow-up, and also enables joints to enter or be withdrawn from the study at any time. The annual failure rate is calculated, and survival rate is cumulated for each successive year. A variety of endpoints were used, including revision for any cause, aseptic revision and cumulative survival. The $95 \%$ confidence intervals were calculated using the Rothman equation. ${ }^{6,7}$

\section{Results}

A total of 258 knees, 115 knees in 101 men and 143 knees in 20 women, had the Kinemax knee implanted. Their mean age was 68 years (36 to 85 ). Of the 49 patients (52 knees), who were not reviewed, 26 (28 knees) did not ask for an appointment, 20 (21 knees) did not respond or did not attend their appointment, and three (three knees) had died of unrelated causes. There were 206 knees $(80 \%)$ left in the study (116 in 98 women and 90 in 77 men); of these, 144 were unilateral single joint arthroplasties and 31 were bilateral (28 staged, three simultaneous). The mean follow-up was for two years (2 to 3). A total of 130 knees $(63 \%)$ had obtained a satisfactory result, with the patient experiencing no or minimal pain and a range of movement of at least $0^{\circ}$ to $90^{\circ}$ in a stable knee.

In 76 knees $(37 \%)$ the result was unsatisfactory. Ongoing pain, for which no cause was found, was present in 14 patients (15 knees) and one patient (one knee) had developed a complex regional pain syndrome. Re-operation had been undertaken in 29 patients (30 knees, 15\%) and a further 29 patients ( 29 knees, $14 \%$ ) had been recommended to have a revision, but had either declined further surgery at present or were on the waiting list (Fig. 2).

Alignment of the implants. The mean angle of the tibial component was $3.1^{\circ}$ of varus (SD 2.4) for the whole group. Of the 206 knees accepting an error of $3^{\circ}$ of valgus to $3^{\circ}$ of varus as a reasonable margin of accuracy for the horizontal tibial cut, $73(35 \%)$ were found to lie beyond $3^{\circ}$ of varus (Fig. 3). There were 80 knees $(39 \%)$ with more than $8^{\circ}$ of valgus of the femoral component (mean $8.20^{\circ}$, SD 2.35). The femoral components were oversized in 75 knees $(36 \%)$ and the tibial component too large in 80 (39\%). Both components were oversized in 37 knees $(18 \%)$.

Re-operation/revision. Revision operations were carried out in ten knees in ten men and 20 knees in 19 women with mean ages of 70 years (50 to 81 ) and 67 years (46 to 83) respectively. Revision was required for infection in three patients, two in the first year and another at 24 months. There were eight revisions for malalignment, six for aseptic loosening, one for arthrofibrosis and four for oversized 


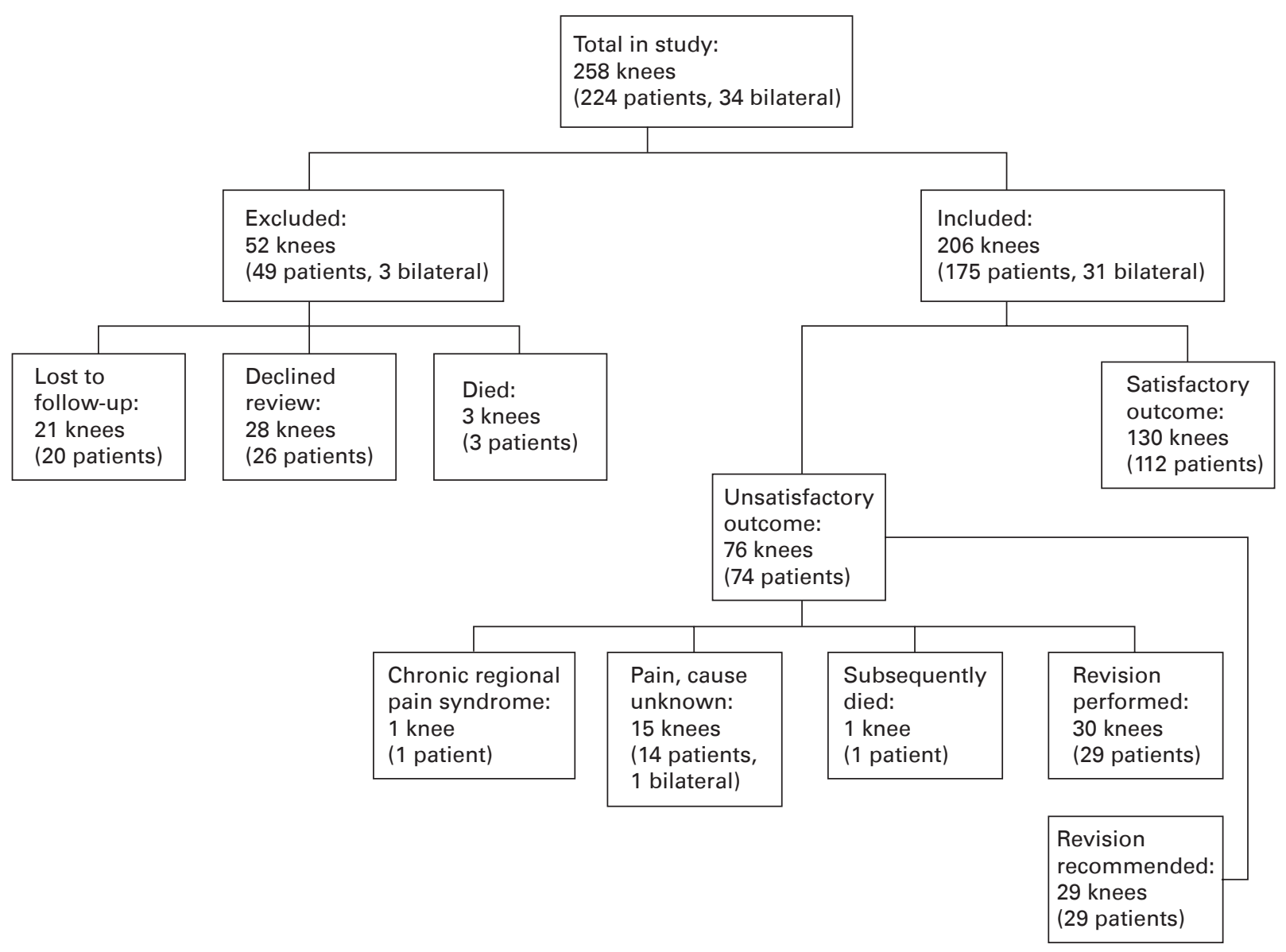

Fig. 2

Flow diagram showing patients in the study.

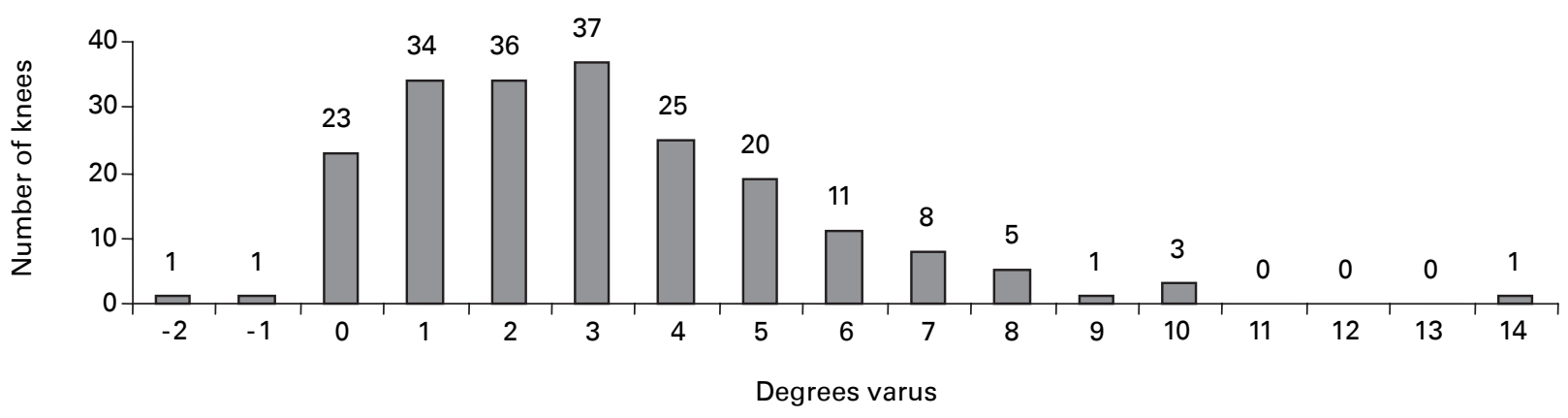

Fig. 3

Histogram showing the distribution of varus angulation of the tibial resection in the cohort.

components. In a further eight patients the patella was resurfaced as a secondary procedure (Table I).

Survival analysis. The overall cumulative survival rate with re-operation of any kind as the endpoint was $79.2 \%$ at three years (95\% confidence interval (CI) 69.2 to 86.8). If aseptic revision was used as the endpoint, including revision for malalignment, oversizing, instability or aseptic loosening, but not including infection or secondary patellar resurfacing, the cumulative survival rate was $85.3 \%$ (95\% CI 75.9 to 91.8 ) at three years. The cumulative survival rate in patients who have been recommended revision but have either declined or were awaiting surgery was $75.9 \%(80.3 \%, 95 \%$ CI 69.5 to 85.3$)$ at three years (Table II, Fig. 4). 
Table I. Reason for revision

\begin{tabular}{|c|c|c|}
\hline Reason for revision & Number of knees & Mean number of months to failure (range) \\
\hline \multicolumn{3}{|l|}{ Septic } \\
\hline Infection & 3 & 15.3 (9 to 24$)$ \\
\hline \multicolumn{3}{|l|}{ Aseptic } \\
\hline Loosening of the tibial component & 3 & 26.7 (14 to 34$)$ \\
\hline Loosening of the femoral component & 1 & 29 \\
\hline Loosening of both components & 2 & 23.5 (11 to 25$)$ \\
\hline Malalignment & 8 & $19.5(11$ to 28$)$ \\
\hline Oversize & 4 & 17.8 (13 to 20$)$ \\
\hline Arthrofibrosis & 1 & 19 \\
\hline Secondary patellar resurfacing & 8 & 17.8 (1 to 26$)$ \\
\hline
\end{tabular}

Table II. Life table showing cumulative survival data and 95\% confidence interval for overall revision for any cause and aseptic revision

\begin{tabular}{|c|c|c|c|c|c|c|c|c|c|c|}
\hline $\begin{array}{l}\text { Years since } \\
\text { operation }\end{array}$ & $\begin{array}{l}\text { Number } \\
\text { at start }\end{array}$ & Failure & Deaths & Withdrawn & $\begin{array}{l}\text { Lost to } \\
\text { follow-up }\end{array}$ & $\begin{array}{l}\text { Number } \\
\text { at risk }\end{array}$ & $\begin{array}{l}\text { Annual } \\
\text { failure rate (\%) }\end{array}$ & $\begin{array}{l}\text { Annual } \\
\text { success rate (\%) }\end{array}$ & $\begin{array}{l}\text { Cumulative } \\
\text { survival rate (\%) }\end{array}$ & $\begin{array}{l}95 \% \text { confidence } \\
\text { interval }\end{array}$ \\
\hline \multicolumn{11}{|c|}{$\begin{array}{l}\text { Re-operation } \\
\text { any cause }\end{array}$} \\
\hline 0 to 1 & 258 & 4 & 1 & 0 & 49 & 231 & 1.7 & 98.3 & 98.3 & 96.6 to 99.4 \\
\hline 1 to 2 & 204 & 17 & 0 & 43 & 0 & 174 & 9.8 & 90.2 & 88.5 & 82.8 to 92.6 \\
\hline 2 to 3 & 144 & 8 & 2 & 105 & 0 & 86 & 9.3 & 90.7 & 79.2 & 69.2 to 86.8 \\
\hline 3 to 4 & 29 & 0 & 1 & 28 & 0 & & & & & \\
\hline \multicolumn{11}{|c|}{ Aseptic revision } \\
\hline 0 to 1 & 258 & 1 & 1 & 1 & 49 & 232 & 0.4 & 99.6 & 99.6 & 97.2 to 100.0 \\
\hline 1 to 2 & 206 & 11 & 0 & 51 & 0 & 175 & 6.2 & 93.8 & 93.4 & 88.5 to 96.5 \\
\hline 2 to 3 & 144 & 7 & 2 & 107 & 0 & 86 & 8.1 & 91.9 & 85.3 & 75.9 to 91.8 \\
\hline 3 to 4 & 28 & 0 & 1 & 27 & 0 & & & & & \\
\hline
\end{tabular}

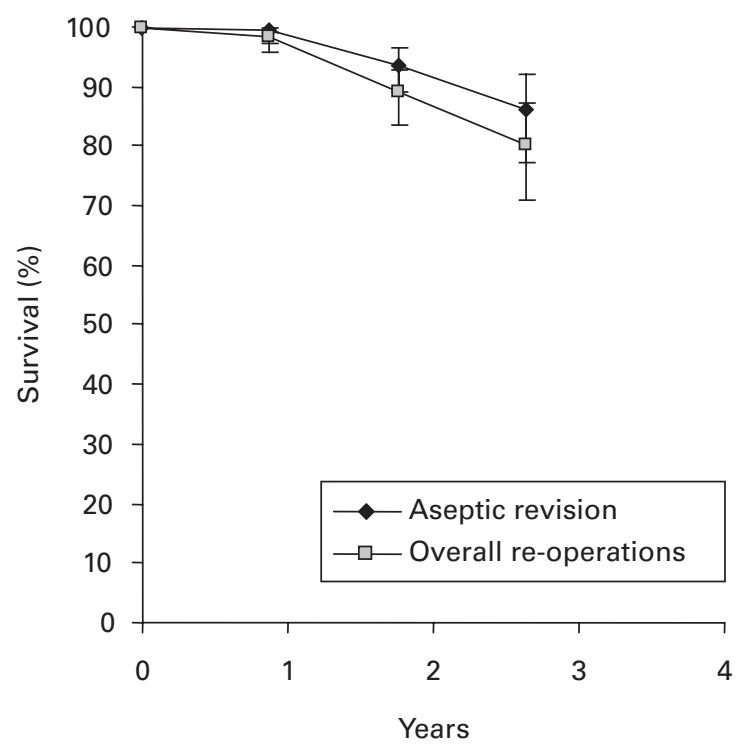

Fig. 4

Survival curve for the cohort. Whiskers indicate $95 \%$ confidence intervals.

\section{Discussion}

In the drive to reduce waiting times it is essential that all patients receive a high quality of treatment in existing NHS hospitals or new facilities. The Weston-Super-Mare NHS
Treatment Centre was an entirely separate facility from the NHS hospital and was staffed by Swedish locums, flown in to perform the operations.

The Kinemax implant has been used widely with good results. Back et $\mathrm{al}^{2}$ reported a series of 422 Kinemax TKRs with a cumulative survival of $99.05 \%$ at three years, $99 \%$ at five years and $96.5 \%$ at nine years. Similarly, an American study by Wright et $\mathrm{al}^{3}$ followed 523 knees for ten years; the overall survival with the risk of re-operation for any cause is as endpoint was $96.1 \%$, and with the risk of aseptic revision as the endpoint was $97.2 \%$.

The Kinemax knee has been used in Sweden with favourable results. The 2007 report from the Swedish Joint Registry $^{8}$ showed that 2487 Kinemax TKRs were performed in Sweden between 1996 and 2005. This number equates to $4.1 \%$ of the total implants used in Sweden. The cumulative revision rate from the Swedish joint registry data is $2.5 \%$ at three years. ${ }^{8}$

Malalignment and oversizing of the components are well known to be modes of failure for TKR. Malalignment increases wear, increases the risk of aseptic loosening, increases the need for revision and worsens the outcome. ${ }^{9,10}$ Malalignment of the components by $10^{\circ}$ increases the load on the tibial plateau by $34 \% .{ }^{10}$ Varus angulation of the tibial component of greater than $3^{\circ}$ is generally accepted as an error in alignment for the normal 
mechanical function of the knee. Many of the arthroplasties performed in Weston-Super-Mare were outside this range.

The results of the Cardiff patients treated at the WestonSuper-Mare Treatment Centre are significantly worse than previously published figures, ${ }^{2,3}$ with a very high revision rate at only three years. This rate continued to rise. There remains a large number of patients disappointed by the outcome of their TKR; many of those who initially refused the offer of revision are now reconsidering their decision. There are also a large number of patients with asymptomatic TKRs with malpositioned or incorrectly-sized components that might still fail. These poor results have resulted in a significant economic impact on our service.

The authors would like to thank the Administrator, Louise College, Cardiff and Vale NHS Trust for their assistance in collection of the data.

No benefits in any form have been received or will be received from a commercial party related directly or indirectly to the subject of this article.

\section{References}

1. No authors listed. BOA. Independent Review of Knee Surgery carried out under the Second Offer Scheme in the NHS Treatment Centre, Weston. BOA Jan 2006.

2. Back DL, Cannon SR, Hilton A, Bankes MJ, Briggs TWR. The Kinemax total knee arthroplasty: nine years experience. J Bone Joint Surg [Br] 2001;83-B:359-63.

3. Wright RJ, Sledge CB, Poss R, et al. Patient reported outcome survivorship after Kinemax total knee arthroplasty. J Bone Joint Surg [Am] 2004;86-A:2464-70.

4. Ewald FC. The Knee Society total knee arthroplasty roentgenographic evaluation and scoring system. Clin Orthop 1989;248:9-12.

5. Armitage P, Berry G. Statistical methods in medical research. Second edition. Oxford: Blackwell Scientific, 1987.

6. Murray DW, Carr AJ, Bulstrode C. Survival analysis of joint replacements. J Bone Joint Surg [Br] 1993;75-B:697-704

7. Rothman KJ. Estimation of confidence limits for the cumulative probability of survival in life table analysis. J Chronic Dis 1978;31:557-60.

8. No authors listed. Annual report. The Swedish joint arthroplasty register 2007. Lund: Wallin \& Dalholm AB:2007. www.ort.lu.se/english (date last accessed 5 December 2008)

9. Kim YH, Kim JS, Yoon S-H. Alignment and orientation of the components in total knee replacement with and without navigation support: a prospective, randomised study. $J$ Bone Joint Surg [Br] 2007;89-B:471-6.

10. Hsu HP, Garg A, Walker PS, Spector M, Ewald FC. Effect of knee component alignment on tibial load distribution with clinical correlation. Clin Orthop 1989;248:135-44. 